\title{
Synthesis and characterisation of novel mutual ester prodrug models of acyclovir
}

Abstract

Background and Objective: Ocular herpes is a recurrent viral infection caused by the herpes simplex virus-1. Herpes simplex virus type one HSV-1 is one of the most common ocular viruses causing subsequent inflammatory responses and corneal blindness worldwide. This study aimed to synthesize a series of novel mutual ester prodrug models to treat viral infection and subsequent inflammation at corneal tissue.

Various formulation strategies have been utilized to improve bioavailability by increasing ocular contact time and improving drug permeation. Chemical approaches, such as prodrug, directed to enhance the ocular bioavailability by improving physicochemical properties of the drug molecule, with the goal of improving drug permeation across cornea.

Methods: Steglich esterification method was to design and synthesis a library of novel mutual prodrugs to increase the bioavailability of acyclovir, owing to enhance the lipophilicity compared with acyclovir. In this study a number of non-steroidal anti-inflammatory drugs (NSAIDs) have been conjugated to acyclovir to improve corneal permeation through enhancing lipophilicity and reduce subsequent inflammation.

Results: The synthesized compounds were characterized through FTIR, ${ }^{1} \mathrm{H}-,{ }^{13} \mathrm{C}-\mathrm{NMR}$ and Mass spectral data. The partition coefficient (logP) of prodrugs were calculated and showed an increment in lipophilicity and permeability in comparison with acyclovir.

Conclusion: The strategy applied to design the novel compound hypothesized to be a novel mutual prodrug, and it may provide a higher absorption than hydrophilic parent (acyclovir) drug with concurrent anti-inflammatory activity.

Keywords: Prodrug; Novel strategy; Acyclovir; Herpes simplex; Ocular delivery; NSAIDs.

\section{Introduction}

The most prevalent serious ocular viral infection in developed countries belongs to herpes simplex virus type 1 (HSV-1) infection. ${ }^{1}$ The incidence and severity of the disease produced by HSV-1 and HSV-2 have been increased from nineties. ${ }^{2}$
The low corneal permeation, cytotoxicity and poor bioavailability of topical eye drops or ointments and/or systemic antiviral agents Triflurothymidin(TFT 3), Idoxuridine (IDU 2), Acyclovir (ACV 1) ointment 3\%, and ganciclovir 4 as shown in Figure 1); restricted their persistent clinical utility. ${ }^{3,4}$

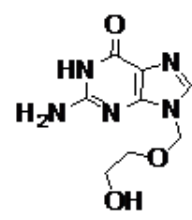

$\mathbf{1}$

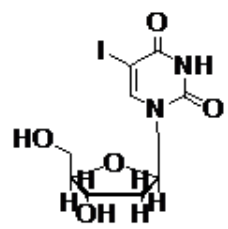

$\mathbf{2}$
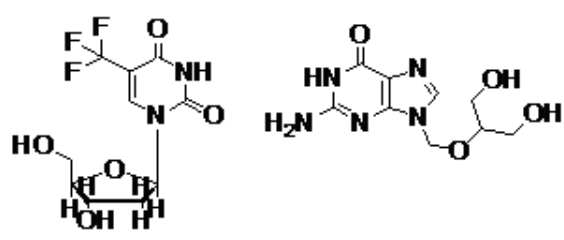

4

Figure 1: Structure of potent nucleoside antiviral analogues: Acyclovir 1; Idoxouridin 2; Trifluorothymidin 3; Ganciclovir 4.

${ }^{1}$ Department of Pharmaceutical Chemistry, College of Pharmacy, Hawler Medical University, Erbil, I raq.

* Correspondence: dana.hamadameen@hmu.edu.krd 
During the last decades, ACV 1 has proved as a potent and safest antiviral agent against $\mathrm{HSV},{ }^{3,5}$ however has some drawbacks, such as low water solubility, which could not be prepared as an eye $\operatorname{drop}^{6,7}$ and low corneal permeability, due to its moderate lipophilicity ( $\log P-1.47){ }^{8}$ Thus, acyclovir 1 may not be effective against ocular herpes infections, ${ }^{7,9}$ hence, ACV 1 has low bioavailability as a result, higher dose and frequent administration is required. ${ }^{3,10}$ Therefore, treatment of herpetic keratitis by utilizing a lipophilic mutual prodrug approach from ACV 1 with non-steroidal anti-inflammatory drugs (NSAIDs), often result in relief of pain for significant period and may overcome the low penetration of acyclovir in cornea as well as the internal ocular tissue can be tremendous on reducing the frequency, severity of recurrent keratitis, risk of corneal scarring and visual loss.

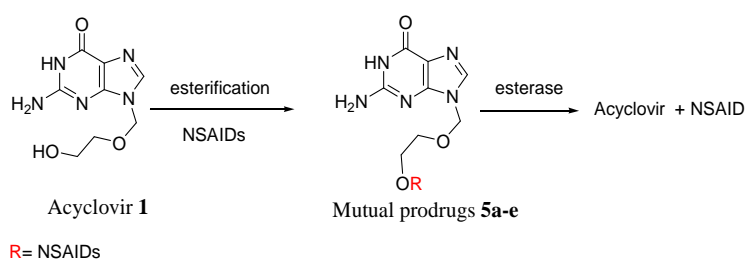

Scheme 1: Proposed synthesis of ACVNSAIDs mutual prodrugs and its hydrolysis inside corneal tissues.

The NSAIDs [lbuprofen, mefenamic acid, flufenamic acid, ketorolac, and tolfenamic acid] are grouped in several classes $(\mathrm{RCOOH})$, have some general properties in common. All of NSAIDs are weak organic acids as given. NSAIDs anti-inflammatory activity is mediated chiefly through inhibition of prostaglandin biosynthesis. ${ }^{11}$ This study aimed to synthesis mutual prodrugs to treat viral infection as well as coexisting eye inflammation and fully characterize the products. It also aimed to see the changes in the lipophilicity of the synthesized compounds by measuring the distribution coefficient $(\log \quad D)$ and of partition coefficient ( $\log P)$.

\section{Methods}

This work has been done at College of Science, Dicle University, Diyarbakir, Turkey, from May 2016 to January 2017.

General Procedure for the Synthesis of Mutual Ester Prodrugs 5a-e

The nonsteroidal anti-inflammatory drug esters of ACV 5a-e were prepared according to a modified procedure reported by Beauchamp et al. ${ }^{12}$ Nonsteroidal anti-inflammatory drugs NSAIDs a-e (2.22 mmol), $\quad N, \quad N$ '-dicyclohexylcarbodiimide DCC (2.22 mmol) and N,N-Dimethylpyridin -4-amine DMAP were dissolved in $15 \mathrm{ml}$ dry dimethylformamide (DMF). The mixture was continuously stirred for 1 hour. under a nitrogen atmosphere at $0^{\circ} \mathrm{C}$. A solution of ACV (2.22 mmol) in DMF $(150 \mathrm{ml})$ was added drop wise to the reaction mixture at $0^{\circ} \mathrm{C}$. The reaction was stirred and allowed to warm up to room temperature. After 24 hours, the reaction was recharged with additional amount of DCC $(2.22 \mathrm{mmol})$ at $0^{\circ}$ C. After 1 hour., the reaction was allowed to warm up to room temperature and stirring was continued under nitrogen atmosphere at ambient temperature for 30 hours. The reaction was monitored by TLC (MeOH-DCM-TEA \{0.5:10:0.2\}) and using of UV lamp, DMF was removed in vacuo and the residue was dissolved in diethyl ether to separate dicyclohexyl urea (DCU). Then, the mixture was filtrated and the solvent was evaporated by rotary evaporator. The residue was chromatographed on silica gel, using (n-hexane-ethylacetate $\{1: 3\}$ ) as the eluent and the products were recrystallized in $\mathrm{n}$-hexane and THF. The ${ }^{1} \mathrm{H}-,{ }^{13} \mathrm{C}-\mathrm{NMR}$ and mass spectra were in consistent with the desired structures. The melting points were determined on a Gallen Kamp electro thermal apparatus by open capillary method and are uncorrected. IR spectra were recorded on FT-IR PerkinElmer (Spectrum-100). ${ }^{1} \mathrm{H}$ and ${ }^{13} \mathrm{C}-\mathrm{NMR}$ spectra were measured by using a Bruker ultra-shield $400 \mathrm{MHz}$ with internal TMS, chemical shifts are given in ppm. The Mass 
spectra were recorded on LC/MS 8040. Log $P$ Calculation: a partitioncoefficient $(P)$ or distribution-coefficient $(D)$ is the ratio of concentrations of a compound in a mixture of two immiscible phases at equilibrium. Partition coefficients of synthesised mutual prodrugs were calculated theoretically through online Virtual Computational Chemistry Laboratory by using (ALOGPS 2.1) program. N-octanol/water calculation by ALOGPS was developed with 12908 molecules from the PHYSPROP database using 75 E-state indices. 64 Neural networks were trained using $50 \%$ of molecules, which selected incidentally from the whole set. The $\log \mathrm{P}$ prediction accuracy is root mean squared error (rms) $=0.35$ and standard mean error $s=0.26$ (Tetko et al., 2001; Tetko and Tanchuk, 2002). The molecular structures of compounds 5a-e were provided as SMILE for (ALOGPS 2.1) applet program. The SMILES were obtained from (ChemDraw Ultra 8.0) software.

\section{Statistical analysis}

All values were reported as mean \pm SEM. The statistical analysis was done using the statistical package for the social sciences (version 23). A value of $P<0.05$ was considered significant.
Instruments

Electric melting points apparatus, Air bath oven, Ultraviolet lamp, FT-IR spectrophotometer, NMR spectrometer, Mass spectrometer.

\section{Results}

Melting points (uncorrected) of the synthesised final compounds were determined and were found to be different from melting points of their starting materials. As shown in (Table 1). The $\mathrm{R}_{f}$ values (DCM-MeOH-TEA $\{10: 0.5: 0.2\}$ ) of the final compounds which showed single round spots appeared after exposing the thin layer chromatograms (TLC) by irradiation with UV light indicating the purity of the synthesized compounds and the completion of the reactions as shown in (Table 1). The partition coefficient (LogP) values were calculated by using Virtual Computational Chemistry Laboratory VCCLab Program, which provides interactive online prediction of $\log \mathrm{P}$ and aqueous solubility of compounds. It can be also used to predict logD values. The SMILE of prodrug structures had been taken by ChemDraw Ultra 8.0 software then used in (ALOGPS 2.1) at VCC-Lab Program site, to calculate LogP of prodrugs as shown in (Table 1).

Table 1: Physical appearance, Melting points and $\mathrm{R}_{f}$ values of starting and final compounds.

\begin{tabular}{lcccc}
\hline products & Percentage of yield \% & Melting Point ${ }^{\circ} \mathbf{C}$ & $\mathbf{R}_{f}$ value & Log P value \\
\hline $\mathbf{5 a}$ & 59 & $160-163$ & 0.84 & $2.48-3.81$ \\
$\mathbf{5 b}$ & 10 & $164-166$ & 0.94 & $3.03-4.20$ \\
$\mathbf{5 c}$ & 17 & $136-139$ & 0.97 & $2.85-4.14$ \\
$\mathbf{5 d}$ & 13 & $170-173$ & 0.87 & $0.59-1.54$ \\
$\mathbf{5 e}$ & 50 & $171-172$ & 0.90 & $3.25-4.01$ \\
\hline
\end{tabular}




\section{Infra-Red Spectroscopy (FT-IR)}

The FT-IR spectra of the synthesised compounds 5a-e with the characteristic bands and its interpretation were presented in (Table 2) showed a characteristic bands of absorption which is in consistence with the proposed structures of the synthesised compounds.
${ }^{1} \mathrm{H}$ - and ${ }^{13} \mathrm{C}$-NMRandMass Spectroscopy of Synthesised Compounds

The characteristic signals of ${ }^{1} \mathrm{H}$ - and ${ }^{13} \mathrm{C}-\mathrm{NMR}$ Spectra of compounds 5a-e were in consistence with their structures. ${ }^{1} \mathrm{H}$-NMR and ${ }^{13} \mathrm{C}$-NMR data with their interpretation are presented in (Tables 2). Mass spectrum of synthesised compounds 5a-e shown in (Table 2)

Table 2: Spectroscopic characterisation of the synthesised compounds 5a-e.

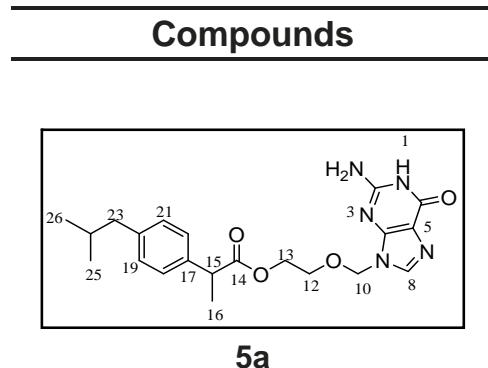

$5 a$

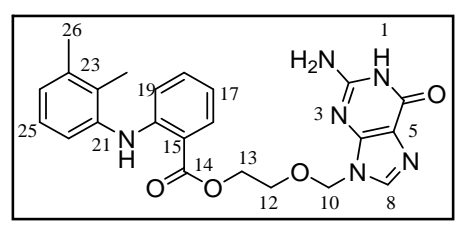

$5 b$

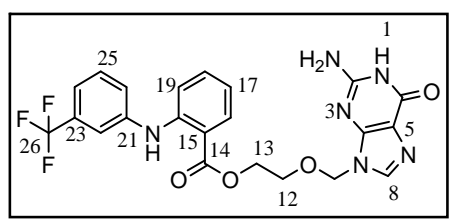

$5 c$
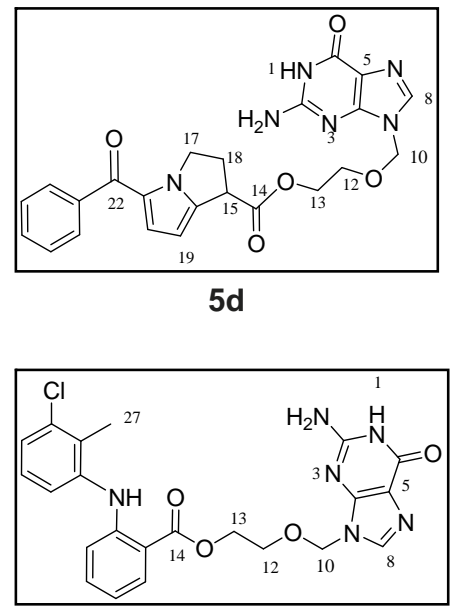

$5 e$

\section{Spectral Data}

IR (cm ${ }^{-1}$ bands): 3300, 3293 ( $\mathrm{NH}_{2}$ str.), 1772 (C=O str. ester), 1653 ( $\mathrm{C}=\mathrm{O}$ str. amide), 1225 (C-O str. ester).

${ }^{1} \mathrm{HNMR}\left(400 \mathrm{MHz}\right.$, DMSO- $\left.d_{6}\right): \delta 8.33(\mathrm{~d}, 1 \mathrm{H}, \mathrm{NH}, 1 \mathrm{H}, \mathrm{CH}-8, \mathrm{ACV}$, $J=8 \mathrm{~Hz}$ ), 7.02-7.22(m, 5H, Ar., $\mathrm{NH}), 5.6\left(\mathrm{~d}, 1 \mathrm{H}, \mathrm{Ar}-\mathrm{CHCO}, \mathrm{CH}_{2}-10\right.$, $J=8 \mathrm{~Hz}), 3.83-4\left(\mathrm{t}, 4 \mathrm{H}, 12 \mathrm{CH}_{2}, 13 \mathrm{CH}_{2}\right)$.

${ }^{13}$ CNMR (101 MHz, DMSO- $d_{6}$ ): $\delta \mathrm{C}_{26}-32.16, \mathrm{C}_{25}-32.29, \mathrm{C}_{16}-33.83$

$\mathrm{C}_{15}-43.56, \mathrm{C}_{23}-44.71, \mathrm{C}_{13}-47.98, \mathrm{C}_{10}-50.14, \mathrm{C}_{12}-53.36, \mathrm{Ar}-139$.

74-127.70, $\mathrm{C}_{2}-153.98, \mathrm{C}_{6}-157.80$, and $\mathrm{C}_{14}-171.98$ $\mathrm{MS}(\mathrm{m} / \mathrm{z})\left(\mathrm{ESI}^{+}\right)[\mathrm{M}-1]^{+}=412$

IR (cm ${ }^{-1}$ bands): 3350.44, 3306.91 ( $\mathrm{NH}_{2}$ str.), 1763 (C=O str. ester), 1675 (C=O str. amide), 1225.2 (C-O str. ester).

${ }^{1} \mathrm{HNMR}\left(400 \mathrm{MHz}, \mathrm{DMSO}-d_{6}\right): \delta 7.97(\mathrm{~d}, 1 \mathrm{H}, \mathrm{NH}, \mathrm{H}-8, \mathrm{Ar}, J=8 \mathrm{~Hz})$, 6.70-7.50 (m, Ar.), 4.15(t, $\left.12 \mathrm{CH}_{2}, 13 \mathrm{CH}_{2}\right)$.

${ }^{13} \mathrm{CNMR}\left(101 \mathrm{MHz}\right.$, DMSO- $\left.d_{6}\right): \delta \mathrm{C}_{26}-25.59, \mathrm{C}_{27}-25.52, \mathrm{C}_{13}-40.57$, $\mathrm{C}_{10}-49.48, \mathrm{C}_{12}-53.95, \mathrm{Ar}-140.53-115.71, \mathrm{C}_{8}-143.76, \mathrm{C}_{6}-154.25$, and $\mathrm{C}_{14}$ $-168.78$.

IR ( $\mathrm{cm}^{-1}$ bands): 3268.02 (b, $\mathrm{NH}_{2}$ str.), 1619 (C=O str. ester), 1585 ( $\mathrm{C}=\mathrm{O}$ str. amide), 1110.2 (C-O str. ester).

${ }^{1} \mathrm{HNMR}\left(400 \mathrm{MHz}\right.$, DMSO- $\left.d_{6}\right): \delta 9.56(\mathrm{~s}, 1 \mathrm{H}, \mathrm{NH}-1), 8.33(\mathrm{~d}, 1 \mathrm{H}, \mathrm{NH}$,

$\mathrm{H}-8, \mathrm{~J}=8 \mathrm{~Hz}$ ), 6.70-7.50(m, Ar.), 4.15(t, 4H, CH $2.12, \mathrm{CH}_{2}-13$ ).

${ }^{13}$ CNMR (101 MHz, DMSO- $\left.d_{6}\right): \delta \mathrm{C}_{13}-43.43, \mathrm{C}_{10}-50.24, \mathrm{C}_{12}-53.43$, Ar-143.85-115.43, $C_{26}-124.57, C_{2}-153.83, C_{6}-160.44$, and $C_{14}-171.14$. $\mathrm{MS}(\mathrm{m} / \mathrm{z})\left(\mathrm{ESI}^{+}\right)[\mathrm{M}]=488$

IR (cm ${ }^{-1}$ bands): 3383, 3439 ( $\mathrm{NH}_{2}$ str.), 3303 ( $\mathrm{NH}$ str.), 1698 (C=O str. ester), 1648 ( $\mathrm{C}=\mathrm{O}$ str. amide), 1272 (C-O str. ester).

${ }^{1} \mathrm{HNMR}\left(400 \mathrm{MHz}, \mathrm{CDCl}_{3}\right): \delta 7.84(\mathrm{~d}, 1 \mathrm{H}, \mathrm{NH}, \mathrm{H}-8, \mathrm{~J}=12 \mathrm{~Hz})$,

6.85(s, $\left.\mathrm{NH}_{2}\right), 6.86-7.53(\mathrm{~m}, \mathrm{Ar}),. 5.73\left(\mathrm{~d}, 2 \mathrm{H}, \mathrm{CH}_{2}-10\right), 4.55(\mathrm{t}, 4 \mathrm{H}$, $\left.\mathrm{CH}_{2-12}, \mathrm{CH}_{2}-13\right)$.

${ }^{13} \mathrm{CNMR}\left(101 \mathrm{MHz}, \mathrm{CDCl}_{3}\right): \delta \mathrm{C}_{18}-25.45, \mathrm{C}_{17}-32.94, \mathrm{C}_{15}-32.96$,

$\mathrm{C}_{13}-44.44, \mathrm{C}_{10}-47.64, \mathrm{C}_{12}-48.43, \mathrm{C}_{19}-102.51, \mathrm{Ar}-139.14-125.06$, $\mathrm{C}_{6}-143.25, \mathrm{C}_{14}-169.79$, and, $\mathrm{C}_{22}-185.08$. $\mathrm{MS}(\mathrm{m} / \mathrm{z})\left(\mathrm{ESI}^{+}\right)[\mathrm{M}-2]=460$.

IR (cm ${ }^{-1}$ bands): 3350.44, $3308.63\left(\mathrm{NH}_{2}\right.$ str.), 1765 (C=O str. ester), 1671 (C=O str. amide), 1229.69(C-O str. ester).

${ }^{1} \mathrm{HNMR}\left(400 \mathrm{MHz}, \mathrm{DMSO}-d_{6}\right): \delta 8(\mathrm{~d}, 1 \mathrm{H}, \mathrm{NH}, \mathrm{H}-8, \mathrm{Ar}, \mathrm{J}=8 \mathrm{~Hz})$, 6.84-7.66(m, NH $\mathrm{NH}_{2}$ Ar.), 5.6 (bs, $\left.2 \mathrm{H}, \mathrm{CH}_{2}-10\right)$, 4.15(t, $12 \mathrm{CH}_{2}, 13 \mathrm{CH}_{2}$ ). ${ }^{13}$ CNMR (101 MHz, DMSO- $\left.d_{6}\right): \delta C_{14}-168.32, C_{6}-154.19, C_{2}-154.06$, $\mathrm{C}_{8}-143.17, \operatorname{Ar}-143.07-117.83, \mathrm{C}_{12}-53.97, \mathrm{C}_{10}-53.86, \mathrm{C}_{13}-49.52$, and $\mathrm{C}_{27}-30.72$.

$\operatorname{MS}(\mathrm{m} / \mathrm{z})\left(\mathrm{ESI}^{+}\right)[\mathrm{M}]=468$. 


\section{Discussion}

The reaction sequences for the synthesised compounds are outlined in scheme (2). Esterification of different NSAIDs a-e were achieved through activation of carboxylic group by the aid of coupling reagents, such as $N$, $N$ '-dicyclohexylcarbodiimide (DCC) and $N$, $N$-Dimethylpyridin-4-amine (DMAP) as a catalyst. As the mechanism of acid esterification is a nucleophilic substitution, there were a number of dried polar aprotic solvents were tried with intermediate polarity in this reaction, such as dichloromethane DCM, tetrahydrofuran (THF) and (DMF). The best solvent was (DMF) due to the high solubility of acyclovir in it. It was sparingly soluble in (DCM) and (THF), but it was soluble in (DMF) by warming on steam bath. After 24 hours, the reaction was recharged with $\mathrm{DCC}$ at $0^{\circ} \mathrm{C}$ in order to activate the remaining acid, then after, 30 hours. of continuous stirring under nitrogen, the reaction stopped. The condition of the reaction was too sensitive to air, that's why it was performed under nitrogen and at ambient temperature. The mixture was filtered to separate the formed dicyclohexylurea(DCU), and DMF was removed from the filtrate in vacuo; then, the filtrate was precipitated in diethyl ether to separate the remaining $\mathrm{DCU}$. One of the simplest methods for esterification of the hydroxyl group of ACV 1 is Steglich esterification method, which is a mild and most convenient method for esterification of acid labile and sterically demanding substrates; by employing DCC as a coupling reagent and DMAP as an auxiliary nucleophile. The mechanism involves two steps; the first, is the conversion of carboxylic acid group of NSAIDs a-e to $O$-acylisourea intermediate, which offers reactivity similar to the corresponding carboxylic acid anhydride, and the second, is conversion of O-acylisourea to ACV ester through nucleophilic substitution reaction. The overall mechanism is shown in the following Scheme (2): The NSAIDsa-e was firstly dissolved in DMF with an equal equivalent amount of DCC and a catalytic amount of DMAP in order to activate the carbonyl group of carboxylic acid to be easily attacked by hydroxyl group of acyclovir (Scheme 2). An auxiliary nucleophile DMAP was used as a stronger nucleophile than hydroxyl group of acyclovir reacts with O-acylisourea6 leading to a reactive amide. This intermediate cannot form intramolecular side products, but reacts rapidly with hydroxyl group of acyclovir. The catalyst DMAP acts as acyl transfer reagent in this way, and subsequent reaction with the alcohol yield the ester. According to a simply modified procedure of Beauchamp et al. and Anand and Mitra ${ }^{12}$ ACV 1 solution in DMF was added to the

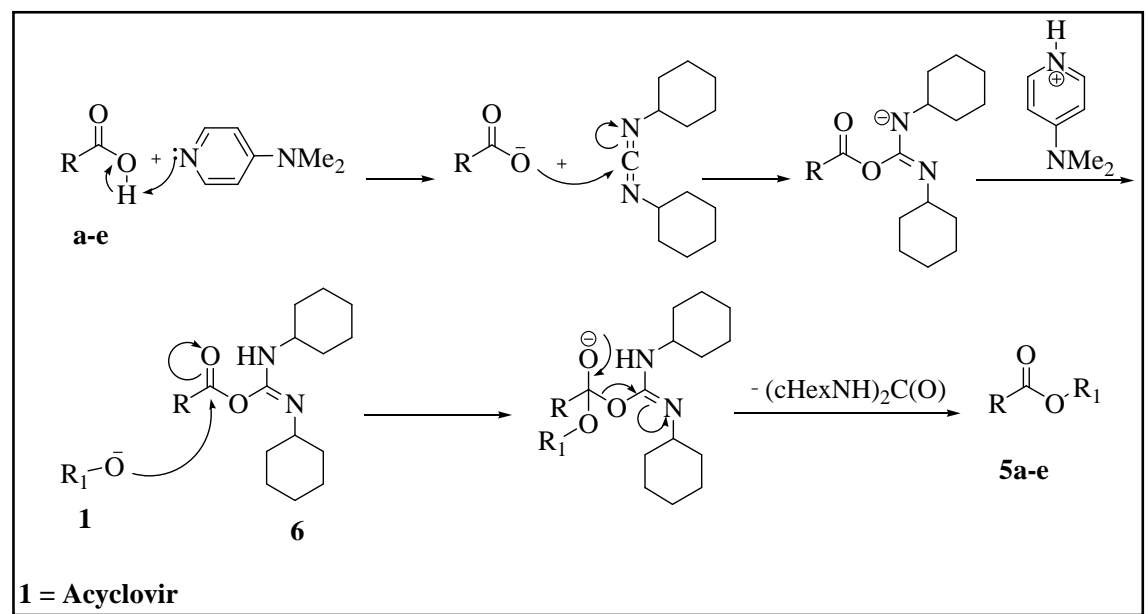

Scheme 2: Mechanistic pathway of esterification using Steglich method. 
mixture of activated carboxylic acid, DCC and DMAP to form an ester and the stable form of dicyclohexylurea DCU. The solution of ACV 1 was added to the mixture (acids a-e, DCC and DMAP) at $0^{\circ} \mathrm{C}$ to avoid formation of side products from a reaction between amino group of ACV 1 and carbonyl group of NSAIDs a-e. Synthesised prodrugs were purified by column chromatography through using ( $n$-hexaneethyl acetate $\{1: 3\}$ ) as a mobile phase. The fractions were collected and the solvents were evaporated under vacuum then dried. The infrared spectra of (5a-e) confirm the esterification of $\mathrm{COOH}$ and $\mathrm{OH}$ functional groups of acids (a-e) and ACV 1 by showing the absorption band of the ester-carbonyl group at $1772 \mathrm{~cm}^{-1}$ for (5a), at $1763 \mathrm{~cm}^{-1}$ for (5b), at $1619 \mathrm{~cm}^{-1}$ for (5c), at $1698 \mathrm{~cm}^{-1}$ for (5d), and at $1765 \mathrm{~cm}^{-1}$ for (5e) (Table 2). The IR spectra show no bands for $(\mathrm{COOH})$ of NSAIDs and hydroxyl $(\mathrm{OH})$ of ACV. The ${ }^{1} \mathrm{H}-\mathrm{NMR}$ spectra of all compounds 5a-e showing a multiplet signals around (4 ppm) due to an overlap of the methylene group at position 12 and $13\left(\mathrm{O}=\mathrm{COCH}_{2}-\mathrm{CH}_{2}-\mathrm{O}-\right)$ of ACV 1 , because the methylene groups surrounded by o xygen at both sides their signals are close to each other and show a multiplet signal. ${ }^{13,14}$ The ${ }^{1} \mathrm{H}$-NMR of methylene group shows signals at 3.83-4 ppm for compound (5a), at 4.12-4.19 ppm for compound (5b), at 3.72-3.74 ppm for compound (5c), at 3.87-4 ppm for compound (5d), and 4.14-4.17 ppm for compound (5e). The second important characteristic peak in ${ }^{1} \mathrm{H}-\mathrm{NMR}$ is the presence of a doublet signal around (8 ppm) due to hydrogen of methine $(\mathrm{CH}-8)$ in hypoxanthine ring and in some reference showed this signal might be due to proton of both $\mathrm{NH}$ of the acids (b, c and e) and $\mathrm{CH}-8$ functionality which appears near to each other as a doublet. ${ }^{15}$ The ${ }^{13} \mathrm{C}$-NMR spectra of (5a-e)support the infrared finding data, by showing the signals around (160 ppm) due to carbonyl carbon atom of ester bond; at $171.98 \mathrm{ppm}$ for (5a), at 168.78 ppm for(5b) (Table 2), at $167.84 \mathrm{ppm}$ for (5c), at $169.79 \mathrm{ppm}$ for (5d), and at 168.32 ppm for (5e). The other exhibiting ${ }^{13} \mathrm{C}-\mathrm{NMR}$ signals are in consistent with their assignment structures. Further verification was given in mass spectrum for $5 a, 5 c$, and $5 \mathrm{~d}$. The mass spectrum of $5 \mathrm{a}$ (Table 2) shows the molecular ion peak with $\mathrm{m} / \mathrm{z}=412$ which is due to the suggested molecular structure of $5 \mathrm{a}$. The mass spectrum of 5 cshows the molecular ion peak at $\mathrm{m} / \mathrm{z}=536$ due to the presence of Formic acid $(\mathrm{HCOOH})$ as it has been used as a polarized substance (Table 2). The molecular ion peak at 488 is due to the suggested structure of the synthesised prodrug 5c. The molecular ion fragments at the imidazole ring to give ions with $\mathrm{m} / \mathrm{z}=$ 463. A series of molecular ion fragments occur due to fragmentation of $2-\mathrm{NH}_{2}$ and Fluorine $\left(\mathrm{F}^{9}{ }_{18.999)}\right.$ atom and give ions with $m / z=449,431$ and 413 and this is a good evidence for the fragmentation of $5 c$ (Table 2). The mass spectrum of $5 d$ shows the molecular ion peak with $m / z=460$ correspond to its molecular mass. The partition coefficient (LogP) is a measure of differential solubility of a compound in a hydrophobic solvent (n-octanol) and a hydrophilic solvent (water). The $\log P$ of target compounds 5a-e at Virtual Computational Chemistry Laboratory (VCC-Lab) Programs site, by using (ALOGPS 2.1) program was calculated. The logP values were ranged from (0.59 to 4.20) showed optimal corneal permeability, as the $\log \mathrm{P}$ of ACV 1 is $(-1.47)^{16}$ and calculated $\log P$ by this program is $(-1.42)$. There is no great difference between estimated $\log P$ in (n-octanol/water) and (ALOGPS 2.1) software. ${ }^{16}$ The optimal corneal permeability observed for drugs with $\log \mathrm{P}$ value about two to four. When the drug molecule is highly lipophilic, it will stick inside the lipid membrane of cornea. ${ }^{15}$ Most of the synthesised mutual prodrug Models are within the optimal $\log \mathrm{P}$ range for corneal permeation except of $5 d$ (Table 1). The validated model showed that lipophilicity and molecular size are the 
most important factors that determine the activity of these esters (5a-e).

\section{Conclusion}

On the bases of the presented results, the study concluded that the synthesis of the designed compounds, acyclovir derivatives as a mutual prodrug with non-steroidal anti-inflammatory drugs was successfully achieved. The structural formula were characterized and confirmed by using infra-red spectroscopy (IR), nuclear magnetic resonance spectroscopy (NMR) and liquid chromatography/mass spectroscopy (LC/MS). Purity and characterization of the synthesized compounds were confirmed by determination of physical properties (melting points and $\mathrm{R}_{f}$ values), FT-IR spectroscopy and $1 \mathrm{H}-\mathrm{NMR}$ and ${ }^{13} \mathrm{C}-\mathrm{NMR}$ spectra. Importantly, the partition coefficient of the designed compounds were evaluated by using ALOGPS 2.1 program, the lipophilicity of the final products were estimated and showed an increment. Accordingly, the products will easily bypass the corneal barriers, wherein the esterase enzyme will cleave the bond between acyclovir and non-steroidal anti-inflammatory drugs. Thereafter, acyclovir will cure herpes infection and the non-steroidal anti-inflammatory drugs will treat the subsequent inflammation.

\section{Competing interests}

The authors declare that they have no competing interests.

\section{References}

1. Wald A, Corey L. Persistence in the population: epidemiology, transmission. In: Arvin A, Campadelli-Fiume G, Mocarski E, Moore PS, Roizman B, Whitley R, et al., editors. Human Herpesviruses: Biology, Therapy, and Immunoprophylaxis Cambridge: Cambridge University Press; 2007.

2. Jwala J. Sustained release nanoparticles containing acyclovir prodrugs for ocular herpes simplex keratitis and characterization of folate transport proteins in a corneal epithelial cell line. University of Missouri-Kansas City; 2011.

3. De Clercq E, Field HJ. Antiviral prodrugs - the development of successful prodrug strategies for antiviral chemotherapy. $\mathrm{Br} \mathrm{J}$ Pharmacol 2006; 147(1):1-11.

4. Clercq ED. Selective Anti-Herpesvirus Agents. Antivir Chem Chemother 2013; 23(3):93-101.

5. Coen DM, Schaffer PA. Antiherpesvirus drugs: a promising spectrum of new drugs and drug targets. Nat Rev Drug Discov 2003; 2(4):278-88.

6. H Bundgaard EJ. Water-soluble, solution-stable, and biolabile N-substituted (aminomethyl) benzoate ester prodrugs of acyclovir. Pharm Res 1991; 8(9):1087-93.

7. Hughes PM, Krishnamoorthy R, Mitra AK. Effect of acylation on the ocular disposition of acyclovir. I: Synthesis, physicochemical properties, and antiviral activity of 2'-esters. J Ocul Pharmacol 1993; 9(4):287-97.

8. Hughes PM, Mitra AK. Effect of acylation on the ocular disposition of acyclovir. II: Corneal permeability and anti-HSV 1 activity of 2'-esters in rabbit epithelial keratitis. J Ocul Pharmacol 1993; 9(4):299-309.

9. Anand BS, Nashed YE, Mitra AK. Novel dipeptide prodrugs of acyclovir for ocular herpes infections: Bioreversion, antiviral activity and transport across rabbit cornea. Curr Eye Res 2003; 26(3-4):151-63.

10. Ricciotti E, FitzGerald GA. Prostaglandins and inflammation. Arterioscler Thromb Vasc Biol 2011; 31(5):986-1000.

11. Beauchamp LM, Orr GF, de Miranda de P, Bumette T, Krenitsky TA. Amino acid ester prodrugs of acyclovir. Antivir Chem Chemother 1992; 3(3):157-64.

12. Nashed YE, Mitra AK. Synthesis and characterization of novel dipeptide ester prodrugs of acyclovir. Spectrochim Acta A Mol Biomol Spectrosc 2003; 59(9):2033-9.

13. Santos CR, Capela R, Pereira CSGP, Valente E, Gouveia L, Pannecouque C, et al. Structureactivity relationships for dipeptide prodrugs of acyclovir: Implications for prodrug design. Eur J Med Chem 2009; 44(6):2339-46.

14. Diez-Torrubia A, Cabrera S, de Castro S, García -Aparicio C, Mulder G, De Meester I, et al. Novel water-soluble prodrugs of acyclovir cleavable by the dipeptidyl-peptidase IV (DPP IV/CD26) enzyme. Eur J Med Chem 2013; 70:456-68.

15. Barot M, Bagui M, Gokulgandhi MR, Mitra AK. Prodrug strategies in ocular drug delivery. Med Chem Shariqah United Arab Emir 2012; 8(4):753.

16. Suresh K, Xiadong Z, Ravi TS, Mitra AK. Small neutral amino acid ester prodrugs of acyclovir targeting amino acid transporters on the cornea: possible antiviral agents against ocular HSV-1 infections. Ophthalmol Eye Dis 2010; 2:43. 